\title{
Erratum to: Application of structured illumination to gas phase thermometry using thermographic phosphor particles: a study for averaged imaging
}

\author{
Florian Zentgraf ${ }^{1} \cdot$ Michael Stephan $^{1} \cdot$ Edouard Berrocal $^{2} \cdot$ Barbara Albert $^{3}$. \\ Benjamin Böhm ${ }^{4} \cdot$ Andreas Dreizler $^{1}$
}

Published online: 26 July 2017

(C) Springer-Verlag GmbH Germany 2017

\section{Erratum to: Exp Fluids (2017) 58:82 \\ DOI 10.1007/s00348-017-2364-4}

In the original article, Fig. 3 was published incorrectly by the publisher. The correct Fig. 3 is given below. The original article is updated with the correct figure.

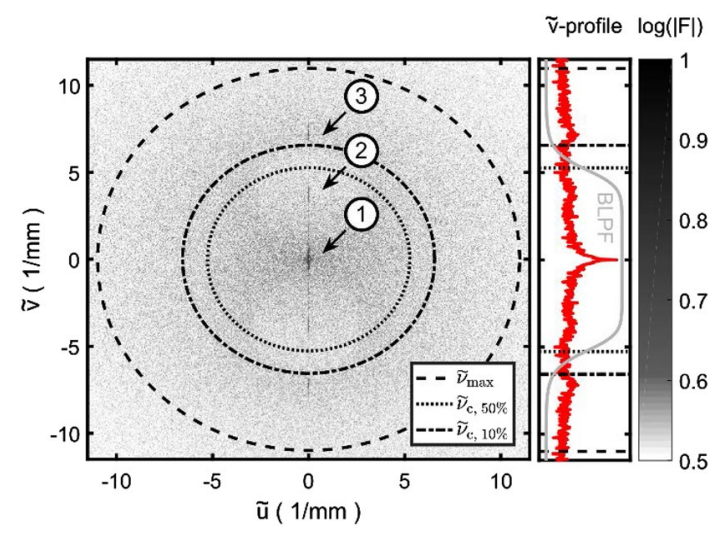

Fig. 3 Fourier spectrum of an $\bar{I}_{\text {SLIPI }}$ image prior to low-pass filtering. Intensities are shown as normalized logarithmic magnitude $\log (|F|)$. Parameters $\tilde{u}$ and $\tilde{v}$ denote the coordinates in the frequency domain. (1)-3) identify prominent frequency components. The $\tilde{v}$ - and BLPFprofile is shown at centerline $\tilde{u}=0 \mu \mathrm{m}^{-1}$. Red camera channel shown at ambient flow temperature. Statistics based on 50 samples

The online version of the original article can be found under doi:10.1007/s00348-017-2364-4.

Florian Zentgraf

zentgraf@rsm.tu-darmstadt.de

1 Department of Reactive Flows and Diagnostics, Technische Universität Darmstadt, Darmstadt, Germany

2 Division of Combustion Physics, Department of Physics, Lund University, Lund, Sweden

3 Eduard-Zintl-Institute of Inorganic and Physical Chemistry, Technische Universität Darmstadt, Darmstadt, Germany

4 Department of Energy and Power Plant Technology, Technische Universität Darmstadt, Darmstadt, Germany 